\title{
Reforma tributária no Brasil: uma necessidade inadiável
}

\author{
Gabriel Bez-Batti ${ }^{1}$
}

\begin{abstract}
Brazil has one of the most complex tax environments in the world. This is due to a large number of laws and regulations dealing with this topic, making the task of both taxpayer and law practitioner quite complicated. The development of the country requires the reform of its tax system. Nevertheless, the task of reforming the system is complicated because Brazil is a federation and the ruler of each government body seems afraid to change the current scenario and therefore lose revenue in consequence of that. The problem is that Brazil is one of the largest economies in the world and requires a more compact tax order, to make easier the entry of money into the country and to give transparency to the citizens, who only feel the will to pay taxes when they can see the amount paid returning in public works and services. I propose two solutions: to uncomplicate the tax system, merging two or more taxes into one; And to reduce the amount spent by the taxpayers to comply with their tax obligations. The idea of the article is to draw a parallel between the solution that the author understands most appropriate and the current measures that have been taken by the legislative and executive branches on the topic.
\end{abstract}

Resumo. O Brasil possui um dos sistemas tributários mais complexos do mundo. Isso se dá pelas inúmeras leis e regulações que tratam da matéria, o que torna a tarefa do contribuinte e do aplicador da lei bastante complicada. O desenvolvimento do país exige a reforma do sistema tributário. Não obstante, a incumbência de reformar o sistema é dolorosa, porque existem inúmeros entes federativos cujos governantes, em tempos de crise, sentem-se receosos de alterar o esquema atual, ante a eventual perda de receita que a mudança possa resultar. O problema é que o Brasil é uma das maiores economias do mundo e requer um sistema tributário mais compacto, que facilite a entrada de dinheiro no País e dê transparência ao cidadão, que só se sente à vontade de pagar tributos quando consegue visualizar o retorno do valor pago em serviços e obras públicas compativeis com o dinheiro arrecadado. Proponho duas soluções: a descomplicação do sistema, a partir do englobamento de vários tributos em um só; e a diminuição do valor despendido pelo contribuinte para cumprir com as obrigações tributárias. A ideia do artigo é traçar um paralelo entre a solução que o autor entende mais adequada e as medidas que vêm sendo tomadas pelos Poderes Legislativo e Executivo acerca do tópico.

\section{Introdução}

É notório que o sistema tributário brasileiro não é um dos mais simples do mundo. Mesmo antes da criação do Código Tributário Nacional, em 1966, profissionais da área já vinham criticando a burocracia que envolve a coleta de tributos no País, seja pelo exagerado número de leis,

\footnotetext{
${ }^{1}$ Pós-graduado em Direito Empresarial pela FGV e LLM Candidate em International Tax Law pela WU Vienna. Email: gabrielbezbatti@gmail.com
} 
que muitas vezes são esparsas e isso dificulta o trabalho dos consultores tributários, seja pela dificuldade do cumprimento das obrigações acessórias, que são complicadas e trazem mais custos para os negócios e para a população em geral. O número de tributos e regulações no País é enorme, e a cada dia que passa a reforma tributária torna-se mais premente. O pleito da população e a reivindicação do ramo empresarial podem fazer parecer que a reforma é fácil. Contudo, uma análise sobre o histórico das propostas revela que apesar do consenso em torno da necessidade de remodelação do sistema tributário brasileiro, pouca coisa foi feita. A razão disso alterna entre a dificuldade da matéria, a inexistência de um consenso de como e onde tributar as riquezas, e pela pouca atratividade do debate da questão pela classe política, que não vê a reforma como um instrumento para arrecadar votos.

Os obstáculos para se atingir a reforma tributária não é exclusividade do Brasil. Nos últimos tempos, soube-se de notícias de que países como os Estados Unidos, a Rússia e a Argentina vinham buscando consenso legislativo para implementar a reforma dentro de seus territórios. Similar ao Brasil, existe uma dificuldade nesses países para se chegar a um acordo sobre o tema. Na verdade, o modo como um país tributa provoca discussões acirradas porque a classe média invariavelmente vai opinar que os ricos não estão sendo tributados suficientemente, e os ricos vão ponderar que um país caro para investir torna a busca por outros locais muito mais atrativa. É um embaraço que exige vontade política para se chegar a um acordo, sob pena de tornar a reforma tributária uma utopia.

O Brasil passa por uma crise econômica e política grave. A recessão causou desemprego, e o apoio à presidente eleita em 2014 se deteriorou a ponto de o povo, representado pelos parlamentares, exigir a sua saída. O atual presidente, então, agora com pouco menos de dois anos de mandato, promoveu-se com a ideia de que, por não buscar a reeleição, medidas impopulares seriam tomadas, a fim de recolocar o País no rumo. Dentre essas medidas, a reforma tributária voltou a ser notícia, e o presidente demonstrou-se disposto a implementá-la a fim de diminuir a burocracia que impede os investimentos no Brasil. Neste paper, tenta-se desvendar os contratempos que tornam a ideia da reforma tributária no País quase impossível, além de analisar o trabalhos recentes desenvolvidos pelos Poderes Legislativo e Executivo acerca do tema. 


\section{O atual Sistema Tributário Nacional e a necessidade urgente de reforma}

O sistema tributário brasileiro é complexo. Além dos 13 impostos estabelecidos pela Constituição Federal ${ }^{2}$, a União está autorizada a criar contribuições sociais, de intervenção do domínio econômico e de interesse das categorias profissionais ou econômicas, como instrumento de sua atuação nas respectivas áreas ${ }^{3}$. Também o Distrito Federal e os municípios foram autorizados, a partir de 2002 (EC n. 39/2002), a criar uma contribuição para o custeio da iluminação pública ${ }^{4}$. Cada ente da tributação pode instituir taxas ${ }^{5}$, em razão do exercício do poder de polícia e para serviços específicos e divisíveis praticados pelo Poder Público, além da contribuição de melhoria ${ }^{6}$, para financiar obras públicas que beneficiam diretamente o contribuinte da obrigação. A União, ainda, pode instituir empréstimos compulsórios para atender despesas extraordinárias definidas na Constituição, e também para investimento público de caráter urgente e de relevante interesse nacional ${ }^{7}$.

Diante desse contexto, percebe-se que em um país com 26 estados e mais um Distrito Federal, além de 5.570 municípios $^{8}$ - cada qual com sua legislação específica -, o número de dispositivos tratando da tributação nacional é irracional, tornando, de fato, o Brasil como um país com um dos sistemas tributários mais complexos do mundo ${ }^{9}$. Não bastasse o elevado número de

\footnotetext{
${ }^{2}$ Como se verá a seguir, à União compete instituir impostos sobre: a) a importação de produtos estrangeiros (II); b) exportação, para o exterior, de produtos nacionais ou nacionalizados (IE); c) renda e proventos de qualquer natureza (IR); d) produtos industrializados (IPI); e) operações de crédito, câmbio e seguro, ou relativas a títulos ou valores mobiliários (IOF); f) propriedade territorial rural (ITR); g) grandes fortunas (IGF). Compete aos estados e ao Distrito Federal instituir impostos sobre: a) transmissão causa mortis e doação (ITCMD); b) operações relativas à circulação de mercadorias e sobre prestações de serviços de transporte interestadual e intermunicipal e de comunicação, ainda que as operações e as prestações se iniciem no exterior (ICMS); c) propriedade de veículos automotores (IPVA). Compete aos municípios e ao Distrito Federal instituir impostos sobre: a) propriedade predial e territorial urbana (IPTU); b) transmissão "inter vivos", a qualquer título, por ato oneroso, de bens imóveis, por natureza ou acessão física, e de direitos reais sobre imóveis, exceto os de garantia, bem como cessão de direitos a sua aquisição (ITBI); c) serviços de qualquer natureza (ISS).

${ }^{3} \mathrm{CF} / 1988$, art. 149

${ }^{4} \mathrm{CF} / 1988$, art. $149-\mathrm{A}$

${ }^{5} \mathrm{CF} / 1988$, art. 145 , II

${ }^{6} \mathrm{CF} / 1988$, art. 145 , III

${ }^{7} \mathrm{CF} / 1988$, art. 148

${ }^{8} \mathrm{O}$ Globo. Com 5 novos municípios, Brasil agora tem 5.570 cidades, jan. 2017, Disponível em: $<$ http://oglobo.globo.com/brasil/com-5-novos-municipios-brasil-agora-tem-5570-cidades-7235803>. Acesso em 12 de abr. 2017.

${ }^{9}$ De acordo com um estudo realizado pelo TMF Group, o sistema tributário brasileiro é o $2^{\circ}$ mais complicado do mundo. Para a empresa de consultoria, a complexidade do sistema tributário brasileiro tem a ver com a forma como a Constituição de 1988 foi elaborada, pois ela deu poder a todos os níveis de governo - federal, estadual e municipal - para cobrar impostos. Por consequência, cada uma das entidades governamentais cria suas próprias regulamentações, a revelar a dificuldade de se entender o sistema. TMF Group. The Financial Complexity Index 2017: Meeting the global challenge of local accounting and tax compliance. Disponível em: <file:///C:/Users/Owner/Downloads/Financial\%20Complexity\%20Index_TMF\%20Group_June2017.pdf>.
} 
leis tributárias, elas são modificadas diariamente ${ }^{10}$. Em 1989, Alfredo Augusto Becker ${ }^{11}$, um dos precursores do Direito Tributário no Brasil, já denunciava no seu livro satiricamente denominado "Carnaval Tributário" que as leis do imposto de renda eram alteradas continuamente por outras leis, decretos-leis, portarias ministeriais, pareceres normativos e outros atos de órgãos governamentais, cuja proliferação era tão rápida e contínua que o Governo não se dava mais ao trabalho de consolidar tudo em novo Regulamento do Imposto de Renda.

O Brasil está colocado na última posição como o lugar onde se gasta mais tempo para cumprir as obrigações tributárias, de acordo com um estudo realizado pela PwC em $2014^{12}$. Nessa pesquisa, identificou-se que, em 2012, o tempo médio para cumprir as obrigações fiscais na América do Sul era de 618 horas, prazo significativamente maior do que a média mundial, de 268 horas, em grande parte impulsionada pelo Brasil, onde se gasta 2.600 horas, e Bolívia, 1.025 horas. Em $2017^{13}$, um novo estudo realizado pela empresa de consultoria revelou que, pela primeira vez, o Brasil reduziu esse tempo para 2.038 horas, devido aos sistemas eletrônicos que vêm sendo utilizados para registrar, preparar e pegar os principais tributos. Isso não foi suficiente, contudo, para tirar o País da última colocação.

Apesar de os números demonstrarem que a complexidade do sistema tributário brasileiro é singular, há especialistas que, além de não acreditarem na reforma tributária, ainda se dizem contrários a ela. É o caso de Paulo de Barros Carvalho ${ }^{14}$, professor da Universidade de São Paulo, que em entrevista concedida em 2010 ao portal Consultor Jurídico apontou que falar em reforma tributária no Brasil é uma ilusão completa, e que desde a Constituição de 1988 não houve qualquer mudança estrutural para tanto. Para o professor, o sistema tributário brasileiro funciona bem e é organizado. Reforçou, ainda, que o sistema brasileiro arrecada e não há necessidade de mudanças a não ser que seja para salvaguardar os direitos dos contribuintes e do fisco. Em agosto de 2016,

\footnotetext{
Acesso em 19 de jul. 2017.

${ }^{10}$ De acordo com um estudo realizado pelo Instituto Brasileiro de Planejamento Tributário, o Brasil cria, em média, 46 novas regras de tributos a cada dia útil.

${ }^{11}$ BECKER, Alfredo Augusto. Carnaval Tributário. São Paulo: Saraiva, 1989.

${ }^{12}$ PwC. Paying Taxes 2014: The global picture. A comparison of tax systems in 189 economies worldwide. Disponível em: <https://www.pwc.com/gx/en/paying-taxes/assets/pwc-paying-taxes-2014.pdf>. Acesso em $12 \mathrm{de}$ abr. 2017.

${ }^{13}$ PwC. Paying Taxes 2017. Disponível em: <https://www.pwc.com/gx/en/paying-taxes/pdf/pwc-paying-taxes2017.pdf>. Acesso em 19 de jul. 2017.

${ }^{14}$ Consultor Jurídico. Sistema tributário funciona e não requer reparos, jan. 2017, Disponível em: <http://www.conjur.com.br/2010-jan-17/entrevista-paulo-barros-carvalho-professor-direito-tributario>. Acesso em 12 de abr. 2017.
} 
Barros Carvalho ${ }^{15}$ renovou a sua opinião no VIII Congresso Internacional de Direito Tributário do Paraná, apontando que a complexidade de organização política brasileira tornou impossível uma reforma tributária.

Ocorre que o país não pode ficar refém da falta de consenso e da falta de vontade política dos governantes para enfrentar as dificuldades em torno do tema, ainda mais diante da segunda pior recessão de sua história ${ }^{16}$. O Brasil está passando por tempos econômicos difíceis e, de acordo com o Economic Forecast Summary, lançado pela OCDE em junho de $2016^{17}$, a profunda recessão deverá continuar em 2017, ante a grande incerteza política e revelações de corrupção em curso, que estão minando a confiança dos consumidores e das empresas, levando a uma contração contínua da procura interna ${ }^{18}$. Apesar da crise, o potencial do mercado brasileiro é fora de dúvida. Com efeito, o Brasil figura em vários rankings como uma das dez maiores economias do mundo ${ }^{19}$; o PIB baseado na paridade de poder de compra (PPP) é de mais de US\$ 3,1 milhões ${ }^{20}$; e as projeções para o futuro colocam o Brasil como uma das cinco maiores economias do mundo ${ }^{21}$, de modo que a vontade política dos governantes em levar a efeito reformas estruturais, como na previdência e nos tributos, deve impulsionar a produtividade e, com isso, os empregos, a arrecadação tributária e o desenvolvimento do País. É diante desses desafios que o presidente Temer ${ }^{22}$, comprometido em realizar as reformas estruturais e impopulares que o Brasil precisa para voltar a crescer, prometeu dedicar esforços para que a reforma tributária se realize em 2017.

\footnotetext{
${ }^{15}$ Jota. Reforma tributária é impossível com organização política atual, diz Paulo de Barros Carvalho, ago. 2016. Disponível em: <https://jota.info/jotinhas/reforma-tributaria-e-impossivel-com-organizacao-politica-atual-diz-paulode-barros-carvalho-31082016>. Acesso em 12 de abr. 2017.

${ }^{16}$ Folha de São Paulo. Brasil vive a segunda pior recessão de sua história, ago. 2016, Disponível em: <http://www1.folha.uol.com.br/paywall/login.shtml?http://www1.folha.uol.com.br/mercado/2016/08/1808803brasil-vive-a-segunda-pior-recessao-de-sua-historia.shtml>. Acesso em 12 de abr. 2017.

${ }^{17}$ Brazil: Economic forecast summary (June 2016), Disponível em <http://www.oecd.org/eco/outlook/brazileconomic-forecast-summary.htm>. Acesso em 10 de fev. 2017.

${ }^{18}$ Original: "the deep recession is set to continue in 2016 and in 2017 against the backdrop of high political uncertainty and ongoing corruption revelations that are undermining consumer and business confidence,leading to a continuous contraction in domestic demand".

${ }^{19} \mathrm{O}$ Brasil é a nona maior economia do mundo, de acordo com o ranking do Fórum Econômico Mundial. WEF. The world?s 10 biggest economies in 2017, mar. 2017, Disponível em: $<$ https://www.weforum.org/agenda/2017/03/worlds-biggest-economies-in-2017/>. Acesso em 19 de jul. 2017.

${ }^{20} \mathrm{IMF}$. Report for Selected Countries and Subjects. Disponível em: http://www.imf.org/external/pubs/ft/weo/2016/01/weodata/weorept.aspx ?sy=2015\&ey=2020\&scsm=1\&ssd=1\&sort= country\&ds=.\&br=1\&pr1.x=54\&pr1.y=7\&c=223\&s=NGDPD\%2CNGDPDPC\%2CPPPGDP\%2CPPPPC\&grp=0\&a=

${ }^{21}$ PwC. The World in 2050 the long view: how will the global economic order change by 2050?. Disponível em: $<$ http://www.pwc.com/gx/en/issues/economy/the-world-in-2050.html>. Acesso em 12 de abr. 2017.

${ }^{22} \mathrm{O}$ Globo. Temer diz que governo vai se empenhar na reforma tributária em $2017 . \quad$ Dez. $2017 . \quad$ Disponível em: <http://oglobo.globo.com/economia/temer-diz-que-governo-vai-se-empenhar-na-reforma-tributaria-em2017-1-20706692>. Acesso em 10 de fev. 2017.
} 


\section{A política tributária desenvolvida pelo Brasil}

O Brasil é uma federação com três níveis de governo, cada qual com competência própria para a instituição de tributos. Como bem aponta Carrazza ${ }^{23}$, no Brasil "o titular da competência tributária não pode nem substancialmente modificá-la, nem delegá-la, nem renunciá-la. Admite-se, porém, que deixe de exercitá-la ou que a exercite apenas em parte". Exceção é o ICMS. Todos os estados devem instituir o imposto sobre circulação de mercadorias, a fim de evitar uma guerra fiscal abusiva e os prejuízos que a race to the bottom pode causar aos estados menos desenvolvidos ${ }^{24}$.

No Brasil existem 12 impostos diferentes ${ }^{25}$. Há ainda a possibilidade de instituição de taxas, contribuições, contribuições de melhoria e empréstimos compulsórios, mas como as taxas e as contribuições de melhoria são alicerçadas no princípio da retributividade ${ }^{26}$ e os empréstimos compulsórios podem ser instituídos apenas para atender despesas extraordinárias definidas na Constituição, e também para investimento público de caráter urgente e de relevante interesse nacional $^{27}$, esse trabalho vai focar na política desenvolvida pelo Brasil com relação aos impostos e as contribuições, principalmente nas contribuições sociais, que só podem ser criadas pela União e integra grande parte da arrecadação federal.

Pois bem, a Constituição Federal de 1988 determinou que a União é competente para instituir IOF, ITR, IPI, Imposto de Importação (II), Imposto de Exportação (IE), Imposto de Renda (IR) e Imposto sobre Grandes Fortunas (IGF). Já os estados são competentes para instituir ICMS, IPVA e ITCMD. Por fim, os municípios são competentes para instituir IPTU, ISS e ITBI. De acordo com Piscitelli, Dain, Rezende e Rosa, citados no trabalho desenvolvido por Azevedo e Melo ${ }^{28}$, o novo arranjo institucional na área tributária decorrente da Constituição de 1988 significou uma transferência real de renda da União para os estados e municípios, esses últimos os mais beneficiados, ocorrendo uma substancial perda relativa da União na participação da receita fiscal. Decorrência disso foi a utilização, pela União, das contribuições sociais como uma alternativa de arrecadação ${ }^{29}$.

\footnotetext{
${ }^{23}$ CARRAZZA, Roque Antônio. ICMS. 16 ed. São Paulo: Malheiros, 2012.

${ }^{24}$ Essa é a opinião, por exemplo, de Barros Carvalho (Curso de Direito Tributário. 27 ed. São Paulo: Saraiva, 2016), para quem o imposto de circulação de mercadorias há de ser instituído e mantido pelos estados, obrigatoriamente, pelas pessoas políticas competentes, no caso estados-membros e Distrito Federal.

${ }^{25} \mathrm{O}$ Imposto sobre Grandes Fortunas nunca foi implementado.

${ }^{26}$ É o princípio informador das taxas, que pressupõe uma contraprestação estatal.

${ }^{27} \mathrm{CF}$, art. 148 .

${ }^{28}$ A política da reforma tributária: federalismo e mudança constitucional. Revista Brasileira de Ciências Sociais. vol. 12, n. 35. Feb/1997.

${ }^{29}$ De acordo com o art. 159, I, da Constituição Federal, a União deverá entregar $49 \%$ do produto da arrecadação dos impostos sobre renda e proventos de qualquer natureza e sobre produtos industrializados ao Fundo de Participação dos
} 
O Brasil, como todos os países da América Latina, possui problemas sociais e de infraestrutura, com um sistema de saúde e educação defasados e falhas no sistema de logística. Ocorre que a arrecadação tributária no Brasil integra grande parte do PIB nacional, a níveis comparados com os países membros da OCDE. Em 2014, a média da tributação em relação ao PIB nos países da OCDE era 34.4, enquanto no Brasil era de 33.4, de acordo com um trabalho desenvolvido pela organização em 2014, intitulado "Estadísticas tributarias en America Latina y el Caribe 1990-2014" ${ }^{30}$. Na América Latina, só a Argentina possui percentual semelhante, beirando 32.2\%. A alta arrecadação, combinada com a precariedade na infraestrutura, aumenta a desconfiança na população, que não consegue visualizar o dinheiro entregue ao governo retornando em políticas públicas. A compreensão de que os impostos são altos e os serviços públicos são fracos resulta em uma população mais propensa a sonegar tributos, o que aumenta o tax gap, ou seja, a diferença entre o total de tributos devidos e os que deveriam ser pagos a tempo. Em estudo realizado pelo Sindicato Nacional dos Procuradores da Fazenda Nacional - Sinprofaz, Rubistein e Vettori ${ }^{31}$ apontaram que "Em 2014, o tax gap nacional representou 23.6\% da arrecadação de impostos no Brasil, representando 8,6\% do PIB" 32 . Para o jurista italiano Luigi Ferrajoli ${ }^{33}$, "se a característica comum das constituições modernas é elevar os direitos sociais à característica de direitos constitucionais, a brasileira deu um passo adiante ao criar garantias de efetivação desses direitos". É de se concordar com o autor. Não obstante, a Constituição resultou em um país caro, o que torna a necessidade de reduzir o tax gap ainda mais evidente; para tanto, a simplificação do sistema tributário é imperativa. Desse modo, e levando-se em conta que a proporção de arrecadação tributária no País comparada ao PIB atinge os níveis dos países desenvolvidos, somos da opinião de que pensar em

estados e do Distrito Federal e ao Fundo de Participação dos municípios. Não há, no entanto, necessidade de repartição das receitas arrecadadas com as contribuições sociais, de modo que a saída encontrada pela União foi arrecadar por essa última via, movimento que gerou reclamação principalmente dos estados. Ver: O Globo. Estados querem fatia da arrecadação com contribuições sociais, fev. 2017, Disponível em: <http://oglobo.globo.com/economia/estadosquerem-fatia-da-arrecadacao-com-contribuicoes-sociais-20931233>. Acesso em 12 de abr. 2017.

${ }^{30}$ OCDE. Revenue Statistics in Latin America and the Caribbean. Disponível em: http://www.oecdilibrary.org/docserver/download/2316133e.pdf?expires=1488722289\&id=id\&accname=ocid177428\&checksum=73 F7638101A97BAEAA2691CE86F0FB45. Acesso em 19 de jul. 2017.

${ }^{31}$ RUBISTEIN, Flavio; VETORI, Gustavo G. Closing the Brazilian Tax Gap: Public Shaming, Transparency and Mandatory Disclosure as Means of Dealing with Tax Delinquencies, Tax Evasion and Tax Planning. Amsterdam: IBFD, mar/2016. Disponível em: https://online.ibfd.org/collections/dfi/printversion/pdf/dfi_2016_01_br_1.pdf. Acesso em 12 de abr. 2017.

${ }^{32}$ Original: in 2014, the national tax gap represented $23.6 \%$ of the aggregate tax revenue collection in Brazil, amounting to $8.6 \%$ of the country?s GDP.

${ }^{33}$ Consultor Jurídico. Constituição brasileira é das mais avançadas do mundo, out. 2013. Disponível em: <http://www.conjur.com.br/2013-out-16/constituicao-brasileira-avancadas-mundo-luigi-ferrajoli>. Acesso em 12 de abr. 2017. 
reforma tributária no Brasil não requer o aumento da carga fiscal total, devendo-se, de início, rever dois pontos: 1) a descomplicação do sistema; 2) e a diminuição do valor despendido para cumprir com as obrigações tributárias, o que minimizaria e muito o custo de investir no País.

\section{A proposta de reforma tributária fatiada do presidente da República}

O governo federal ainda não apresentou um projeto de reforma tributária completo, que possibilite a análise do propósito e das vertentes do executivo nesse assunto específico. Há, porém, indícios de que a reforma será fatiada, realizada por meio de medidas provisórias, que deverão, necessariamente, ser analisadas pelo Congresso Nacional $^{34}$. Ainda que a ideia da descomplicação do sistema tenha sido sugerida pelo governo, muito trabalho há de ser feito para que esse desiderato seja de fato alcançado. Uma das medidas anunciadas pelo governo é a simplificação do PIS e da Cofins, duas contribuições sociais, de competência tributária da União. A ideia é facilitar o sistema, mas manter intacta a carga tributária, e assim preservar a arrecadação. Na verdade, hoje o sistema do PIS e da Cofins funciona da seguinte forma: as empresas que são tributadas pelo lucro real, no regime de imposto de renda, devem seguir o regime não-cumulativo, que tem uma alíquota maior mas possibilita o abatimento por meio de créditos tributários. Já as empresas que optaram pelo lucro presumido ou arbitrado pagam uma alíquota menor, só que elas não têm direito de crédito. Porém, as empresas que optam pelo regime do lucro presumido do imposto de renda e, consequentemente, pela alíquota menor no sistema cumulativo do PIS e da Cofins, temem que a simplificação das alíquotas ocasione a supressão do regime cumulativo, além da majoração da alíquota menor. Foi negativa a repercussão da medida no setor de serviços ${ }^{35}$, cujas empresas, em sua grande maioria, optam pelo regime do lucro presumido.

Como apontado, a proposta do governo ainda não foi divulgada, porém a crítica, desde já, deve ser feita. Isso porque, apesar de a grande maioria das empresas no Brasil optarem ou pelo regime do Simples Nacional, ou pelo regime do lucro presumido, as pessoas jurídicas que optaram pelo regime do lucro real satisfazem $85 \%$ da arrecadação do Imposto de Renda sobre Pessoas Jurídicas $^{36}$. Esse dado deve refletir na arrecadação das contribuições sociais, pois em todas a ocor-

\footnotetext{
${ }^{34}$ Folha de São Paulo. Temer anuncia reforma tributária fatiada e com início no $1^{\circ}$ semestre, mar. 2017, Disponível em: <http://www1.folha.uol.com.br/mercado/2017/03/1864304-temer-anuncia-reforma-tributaria-fatiada-e-cominicio-no-1-semestre.shtml>. Acesso em 12 de abr. 2017.

${ }^{35}$ Época Negócios. Empresários alertam para reforma do PIS/Cofins, dez. 2016, Disponível em: $<$ http://epoca.globo.com/economia/noticia/2016/12/empresarios-alertam-para-reforma-da-piscofins.html>. Acesso em 12 de abr. 2017.

${ }^{36}$ Câmara dos Deputados. Projeto de Lei n. 4.765/2005. Disponível em:
} 
rência do fato gerador depende do sucesso da atividade. Ora, se a quantidade de empresas que optaram pelo lucro real é menor e ainda assim a arrecadação corresponde a essa exuberante quantia, não é necessário um estudo para afirmar que a capacidade contributiva das empresas optantes pelo lucro real é maior que a das outras empresas. Por isso, se se exige o aumento de tributo para simplificação do PIS e da Cofins, quem deve suportar a carga são as empresas maiores, optantes pelo lucro real. Além disso, se a proposta é simplificar, que se faça um trabalho bem feito. Ainda que seja difícil a criação de um IVA nacional, cobrado na venda e que substituísse o PIS, a Cofins $^{37}$, o ISS e o ICMS ${ }^{38}$, como proposto pelo Conselho de Desenvolvimento Econômico e Social $(\mathrm{CDES})^{39}$, deveria-se lançar, então, um projeto que unificasse o PIS, a Cofins, a CIDE Combustíveis e o IPI, ou que unificasse os imposto sobre o consumo (IPI, ICMS e ISS) e transferisse a competência tributária aos estados; ou seja, a modificação da competência tributária depende de um estudo econômico que demonstre a importância de cada tributo na arrecadação das diferentes unidades da federação, cabendo aos legisladores definirem se desejam que a União mantenha grande parte da receita e, ao final, distribua o valor arrecadado entre os estados e os municípios, ou se pretendem que os estados tenham mais autonomia financeira. Ainda assim, a necessidade de simplificação é inegável, e o governo, nessa primeira proposta, parece não ter se apoiado nesse postulado.

Na Câmara dos Deputados, já se discute uma proposta de reforma tributária, com base em projeto da relatoria do Deputado Luiz Carlos Hauly ${ }^{40}$. Ele propõe, por exemplo, que o IPI, o PIS, o ICMS, a Cofins e o ISS sejam incorporados ao IVA, de competência estadual. Quer, ainda, que a CSLL seja incorporada ao IR. Ele pretende. também, que os municípios tenham competência para instituir o ITR e o IPVA. As medidas provisórias lançadas pelo presidente Temer, se aprovadas, irão barrar os trabalhos da comissão especial que já analisa a proposta impulsionada pelo Deputado Hauly. Resta ver, então, como o governo federal e o Congresso Nacional irão

\footnotetext{
http://www.camara.gov.br/sileg/integras/313141.pdf

${ }^{37}$ Note-se que aqui não se discute o aumento da arrecadação por meio das contribuições sociais, mas como deve ser realizada essa repartição.

${ }^{38}$ Folha de São Paulo. Conselhão propõe reforma tributária com fim do ICMS, fev. 2017, Disponível em: <http://www1.folha.uol.com.br/mercado/2017/02/1858851-conselhao-propoe-reforma-tributaria-com-fimdo-icms.shtml>. Acesso em 12 de abr. 2017.

${ }^{39} \mathrm{~A}$ proposta sofre resistência dos estados, que temem perder receita com o fim do ICMS, em um momento de queda na arrecadação.

${ }^{40}$ Câmara dos Deputados. Principais Linhas da Proposta de Reforma Tributária - Dep. Luiz Carlos Hauly. Disponível em: : http://www2.camara.leg.br/atividade-legislativa/comissoes/comissoes-temporarias/especiais/55alegislatura/reforma-tributaria/documentos/outros-documentos/resumo-hauly
} 
se comportar diante da necessidade de reformas estruturais do sistema tributário brasileiro - que não pode se resumir às medidas fatiadas do presidente Temer -, a exigir dois comprometimentos das autoridades: a) a descomplicação do sistema, a partir do englobamento de vários tributos em um só; b) e a diminuição do valor despendido para cumprir com as obrigações tributárias, que é alto no Brasil, porém nada se discutiu sobre o tema até agora. Nessa empreitada, as autoridades também devem estar certas de que quem tem mais dinheiro deve pagar mais tributos, de modo que qualquer modificação para a descomplicação do sistema tributário deve atingir quem pode mais, consignando, porém, que a carga fiscal total deve manter-se nos níveis atuais, porque a arrecadação tributária no Brasil em proporção ao PIB atinge níveis de países desenvolvidos, a demonstrar que o dinheiro existe, e o que falta é aplicação correta dos recursos.

\section{Conclusão}

Conclui-se, então, que a reforma tributária, além de ser tendência mundial, é uma necessidade no Brasil, que como visto tem um sistema tributário bastante complicado. A boa notícia é que o governo atual, após assumir o posto em decorrência do impeachment da ex-presidente Dilma Rousseff, disse não ser avesso a tomar as medidas que o País precisa para voltar a crescer, mesmo que elas sejam impopulares. A má-notícia é que além da necessidade de contar com o apoio do Congresso Nacional para levar adiante as reformas necessárias, o governo não se mostrou disposto, em sua primeira medida, a traçar a solução de dois pontos que devem fazer parte de qualquer discussão sobre o tema no Brasil. A primeira é a descomplicação do sistema tributário, e para tanto medidas profundas, que não se limitem à simplificação das alíquotas, devem ser tomadas. A segunda é a diminuição do valor despendido para cumprir com as obrigações tributárias; o problema é que, mesmo o Brasil estando colocado na última posição como o lugar onde se gasta mais tempo para cumprir as obrigações tributárias, nenhuma discussão efetiva foi feita para resolver o problema. Acreditamos que a solução desses dois pontos aliviariam os gargalos burocráticos que impedem os investimentos no País. Após isso, questões mais específicas como o aumento da alíquota do imposto causa mortis, criação do imposto sobre grandes fortunas, e tributação de dividendos na fonte podem ser realizadas com mais tranquilidade. 


\section{Referências}

BECKER, Alfredo Augusto. Carnaval Tributário. São Paulo: Saraiva, 1989.

Câmara dos Deputados. Principais Linhas da Proposta de Reforma Tributária - Dep. Luiz Carlos Hauly. Disponível em: <http://www2.camara.leg.br/atividade-legislativa/comissoes/comissoestemporarias/especiais/55a-legislatura/reforma-tributaria/documentos/outros-documentos/resumohauly>. Acesso em 12 de abr. 2017.

Câmara dos Deputados. Projeto de Lei n. 4.765/2005. Disponível em: <http://www.camara.gov.br/sileg/integras/313141.pdf>. Acesso em 12 de abr. 2017.

CARRAZZA, Roque Antônio. ICMS. 16 ed. São Paulo: Malheiros, 2012.

Consultor Jurídico. Constituição brasileira é das mais avançadas do mundo, out. 2013, Disponível em: <http://www.conjur.com.br/2013-out-16/constituicao-brasileira-avancadas-mundo-luigiferrajoli>. Acesso em 12 de abr. 2017.

CARVALHO, Paulo de Barros. Curso de Direito Tributário. 27 ed. São Paulo: Saraiva, 2016

Consultor Jurídico. Sistema tributário funciona e não requer reparos, jan. 2010, Disponível em: <http://www.conjur.com.br/2010-jan-17/entrevista-paulo-barros-carvalho-professordireito-tributario>. Acesso em 12 de abr. 2017.

Época Negócios. Empresários alertam para reforma do PIS/Cofins, dez. 2016, Disponível em: <http://epoca.globo.com/economia/noticia/2016/12/empresarios-alertam-para-reformada-piscofins.html>. Acesso em 12 de abr. 2017.

Folha de São Paulo. Brasil vive a segunda pior recessão de sua história, ago. 2016, Disponível em: $<$ http://www1.folha.uol.com.br/paywall/login.shtml?http://www1.folha.uol.com.br/mercado/2016 /08/1808803-brasil-vive-a-segunda-pior-recessao-de-sua-historia.shtml>. Acesso em $12 \mathrm{de}$ abr. 2017.

Folha de São Paulo. Conselhão propõe reforma tributária com fim do ICMS, fev. 2017, Disponível em: <http://www1.folha.uol.com.br/mercado/2017/02/1858851-conselhao-propoe-reformatributaria-com-fim-do-icms.shtml>. Acesso em 12 de abr. 2017.

Folha de São Paulo. Temer anuncia reforma tributária fatiada e com início no $1^{\circ}$ semestre, mar. 2017, Disponível em: <http://www1.folha.uol.com.br/mercado/2017/03/1864304-temer-anunciareforma-tributaria-fatiada-e-com-inicio-no-1-semestre.shtml>. Acesso em 12 de abr. 2017.

IMF. Report for Selected Countries and Subjects. Disponível em: $<\mathrm{http}$ //www.imf.org/external/pubs/ft/weo/2016/01/weodata/weorept.aspx?sy=2015\&ey=2020\&sc $\mathrm{sm}=1 \& \mathrm{ssd}=1 \&$ sort=country $\& \mathrm{ds}=. \& \mathrm{br}=1 \& \mathrm{pr} 1 . \mathrm{x}=54 \& \mathrm{pr} 1 . \mathrm{y}=7 \& \mathrm{c}=223 \& \mathrm{~s}=\mathrm{NGDPD} \% 2 \mathrm{CNGDPDP}$ C\%2CPPPGDP $\% 2$ CPPPPC \&grp $=0 \& a=>$

Jota. Reforma tributária é impossível com organização política atual, diz Paulo de Barros Carvalho, ago. 2016, Disponível em: <https://jota.info/jotinhas/reforma-tributaria-e-impossivel-comorganizacao-politica-atual-diz-paulo-de-barros-carvalho-31082016>. Acesso em 12 de abr. 2017.

O Globo. Com 5 novos municípios, Brasil agora tem 5.570 cidades, jan. 2013. Disponível em: <http://oglobo.globo.com/brasil/com-5-novos-municipios-brasil-agora-tem-5570cidades-7235803>. Acesso em 12 de abr. 2017.

O Globo. Estados querem fatia da arrecadação com contribuições sociais, fev. 2017, 
Disponível em: <http://oglobo.globo.com/economia/estados-querem-fatia-da-arrecadacao-comcontribuicoes-sociais-20931233>. Acesso em 12 de abr. 2017.

O Globo. Temer diz que governo vai se empenhar na reforma tributária em 2017, dez. 2016. Disponível em: <http://oglobo.globo.com/economia/temer-diz-que-governo-vai-se-empenhar-nareforma-tributaria-em-2017-1-20706692>. Acesso em 10 de fev. 2017.

OECD. Brazil: Economic forecast summary (June 2016). Disponível em $<\mathrm{http}$ ///www.oecd.org/eco/outlook/brazil-economic-forecast-summary.htm>. Acesso em 10 de fev. 2017.

OCDE. Revenue Statistics in Latin America and the Caribbean. Disponível em: http://www.oecdilibrary.org/docserver/download/2316133e.pdf?expires=1488722289\&id=id\&accname=ocid1774 28\&checksum=73F7638101A97BAEAA2691CE86F0FB45. Acesso em 19 de jul. 2017.

PwC. Paying Taxes 2014: The global picture. A comparison of tax systems in 189 economies worldwide. Disponível em: <https://www.pwc.com/gx/en/paying-taxes/assets/pwc-paying-taxes2014.pdf>. Acesso em 12 de abr. 2017.

PwC. Paying Taxes 2017. Disponível em: <https://www.pwc.com/gx/en/paying-taxes/pdf/pwcpaying-taxes-2017.pdf>. Acesso em 19 de jul. 2017.

PwC. The World in 2050 the long view: how will the global economic order change by 2050?. Disponível em: <http://www.pwc.com/gx/en/issues/economy/the-world-in-2050.html>. Acesso em 12 de abr. 2017.

RUBISTEIN, Flavio; VETORI, Gustavo G. Closing the Brazilian Tax Gap: Public Shaming, Transparency and Mandatory Disclosure as Means of Dealing with Tax Delinquencies, Tax Evasion and Tax Planning. Amsterdam: IBFD, mar/2016. Disponível em: $<$ https://online.ibfd.org/collections/dfi/printversion/pdf/dfi_2016_01_br_1.pdf>. Acesso em 12 de abr. 2017.

TMF Group. The Financial Complexity Index 2017: Meeting the global challenge of local accounting and tax compliance. Disponível em: <file://C:/Users/Owner/Downloads/Financial\%20Complexity\%20Index_TMF\%20Group_June2 017.pdf>. Acesso em 19 de jul. 2017.

WEF. The world?s 10 biggest economies in $2017 . \quad$ Disponível em: $<$ https://www.weforum.org/agenda/2017/03/worlds-biggest-economies-in-2017/>. Acesso em 19 de jul. 2017. 